\title{
Stocking effectiveness of red sea bream, Pagrus major, in Kagoshima Bay, Japan
}

\author{
HIROTOSHI SHISHIDOU ${ }^{1}$ \\ ${ }^{1}$ Kagoshima Prefectural Fisheries Experimental Station, 11-40 Kinko-cho, Kagoshima 892-0836, Japan \\ (shigen@po.pref.kagoshima.jp)
}

SUMMARY: Red sea bream Pagrus major stock enhancement attempts in Kagoshima Bay were started in the back bay area in 1974. The project has developed into a large-scale operation, and over one million juveniles have been released in the entire bay since 1981. The commercial catch of red sea bream in this bay had decreased temporarily to 71 tons in 1976, but recovered as the project progressed to 213 tons in 1991 . Stocking effectiveness of red sea bream in this bay is evaluated by a fish market census. The census has been mainly conducted at Kagoshima Fish Market about twice a week, where more than $80 \%$ of red sea bream fished in the bay are landed. Red sea bream were classified into wild or released individuals by the deformity of the inter-nostril epidermis (IE's). Appearance rates of the fish which have the deformity of IE's (DIE fish) reared in Kagoshima Mariculture Society are more than $80 \%$. The mixture rate of DIE fish in fishes investigated were between $15.3 \%$ and $73.5 \%$ from 1989 to 2000 . The recapture rate of releases in 1990,9 years after they were released, was estimated to be $8.8 \%$. The ratio of the total landing cash value to the cost of seeds excluding personnel and facilities was estimated to be 6.99 .

KEY WORDS: red sea bream, stocking effectiveness, Kagoshima Bay, fish market census, deformity of the inter-nostril epidermis, mixture rate, recapture rate, economic return rate

\section{INTRODUCTION}

Red sea bream Pagrus major is distributed along the coastal waters of Japan where it is one of the most valuable and popular fish resources. On Kagoshima Bay, it is also common and is fished mainly by pole and line, gillnets, and longline in commercial fisheries, and by recreational angling.

Red sea bream is a good species for stock enhancement programs together with Japanese flounder, about 24 million hatchery-reared juveniles were released on Japanese coastal waters in 1999." Red sea bream stock enhancement project in Kagoshima Bay was started in 1974, and about 0.4 million juveniles were released at 18 stations in the entire bay in 2000 ( Fig.2).

When the project first started, the estimation on the stocking effectiveness depended on the recapture report of tagged releases from fishermen. But the report rates were low, so the estimation was not satisfied. On the other hand, more than $80 \%$ of red sea bream fished in this bay are landed on Kagoshima Fish Market. So a fish market census conducted at this market was devised to estimate them. ${ }^{2)}$ The census has been conducted since 1976 .

This paper will outline a method to estimate the stocking effectiveness of red sea bream in this bay and report recent results.

\section{MATERIALS AND METHODS}

\section{Description of area surveyed}

Kagoshima Bay is a large, semi-enclosed bay

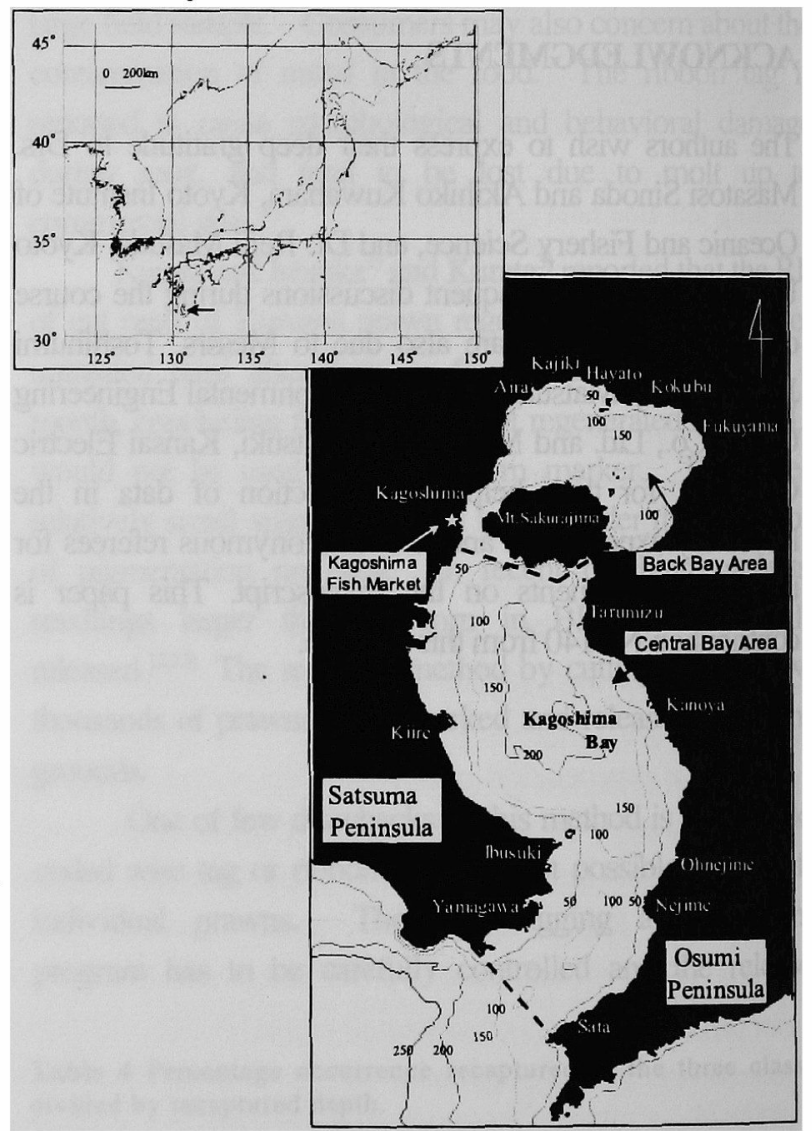

Fig.1 The geographical location and bottom topography of Kagoshima Bay. Bottom contours are in meters.

located in the southernmost part of Kyushu, southwest Japan (Fig.1). Kagoshima Bay is about 80 
$\mathrm{km}$ long and $20 \mathrm{~km}$ wide. The bay is composed of northern and southern basins and a sill between the southern basin and the open sea. These basins are connected by a narrow and shallow channel between Mt. Sakurajima and Kagoshima city. The northern basin, or the Back Bay Area, has a maximum depth of $210 \mathrm{~m}$ and an area of $243 \mathrm{~km}^{2}$. The southern basin and the entrance of the bay, or the Central Bay Area, have a maximum depth of $237 \mathrm{~m}$ and an area of $576 \mathrm{~km}^{2}$, and the average depth of $80 \mathrm{~m}$ and an area of $310 \mathrm{~km}^{2}$ respectively.

\section{Statistics on catch and releasing}

Red sea bream stock enhancement project were started in the back bay area in 1974. It has developed into a large-scale operation, and over one million juveniles have been released at 18 stations in the entire bay since 1981. In recent years, the number of releases have decreased. Over 20 million juveniles have been released in this bay by 2000 (Fig.2). All released juveniles are produced at Kagoshima Mariculture Society since 1989. They are released at about $60 \mathrm{~mm}$ total length from June to July.

The highest levels of commercial catch of red sea bream in this bay was about 150 - 250 tons, up until 1972. After that, it decreased rapidly to 71 tons in 1976, but it recovered as the project progressed to 213 tons in 1991. In recent years, it is about 150 tons (Fig.2).

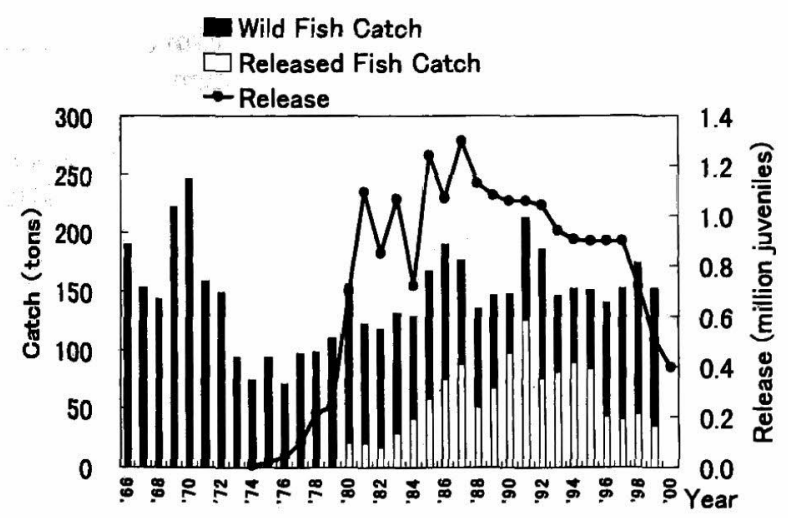

Fig.2 Commercial catch, divided into wild and released fishes, and the number of red sea bream juveniles released in Kagoshima Bay.

\section{Characteristic of released fishes}

A deformity of the inter-nostril epidermis (IE's) was discovered in cultured red sea bream derived from hatchery reared seed by Goto (Fig. 3 ) ${ }^{4}$.) The deformity of IE's (DIE) has not been observed in wild fish. ${ }^{\text {s) }}$ The frequency of occurrence for IE's forming and unformed individuals are fixed approximately 40 days after hatching. ${ }^{6}$ The appearance rates of the fish which have DIE (DIE fish) in landed releases, 1 to 2 years after release, are approximately similar to the rates of the fish landed within the released year, ${ }^{5)}$ The IE's structure for hatchery reared red sea bream rarely changed during an 18 month of breeding observations conducted after hatching. ${ }^{7}$ Therefore, this characteristic is a valid marker that simplifies the detection of hatchery reared red sea bream via fish market census."

Appearance rates of DIE fish reared by Kagoshima Mariculture Society are about more than $80 \%$ (Table 1).

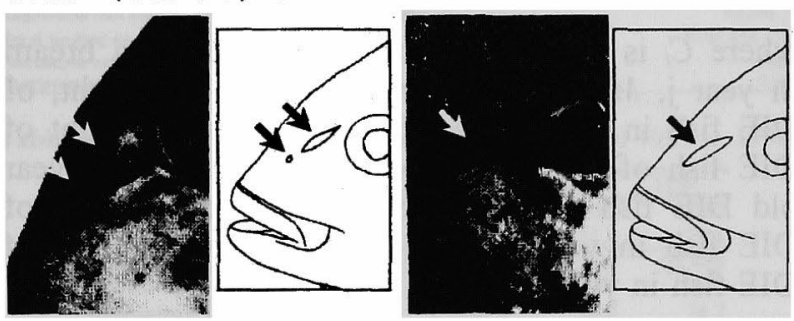

Fig.3 Illustration of a typical red sea bream nostril .

Left: wild (normal: arrows), Right: hatchery reared (DIE: arrows).

Table 1 Annual appearance rates (\%) of DIE fish reared by the Kagoshima Mariculture Society from 1991 to 2000.

\begin{tabular}{ccccccccccc}
\hline \hline Year & 191 & 192 & 93 & 94 & 95 & 96 & 97 & 98 & 99 & 100 \\
\hline & 85.3 & 89.3 & 97.5 & 86.6 & 89.9 & 95.4 & 91.0 & 70.1 & 86.2 & 97.9 \\
\hline
\end{tabular}

\section{Fish market census}

The fish market census to evaluate the stocking effectiveness of red sea bream in this bay has been mainly conducted at Kagoshima Fish Market about twice a week. Red sea bream are classified into wild or released individuals by DIE since 1989 .

This census is used to develop a record of the producer's or associated Fisheries Cooperative Association's address, number of fish caught, the weight of each fish, and the presence of DIE for all fish landed that day. If fish were weighed together, all fish were checked for DIE and the total weight and number were recorded.

\section{Mixture rates}

Annual samples were divided the Back Bay Area, the Central Bay Area, and the Outside of Bay Area, according to the producer's address or Fisheries Cooperative Association (Fig.1) . The mixture rates of DIE fish in fish investigated, were calculated for each area.

\section{Age composition}

Until 1998, the annual samples were resolved from 0 to $8+$ years old by Shiihara's Method, ${ }^{2)}$ based on the relationship between the age and the weight, and they are DIE fish or not. Since 1999, they were resolved by an age-weight key, obtained by examining the otolith ring to determine the age. ${ }^{8)}$ 
In the following estimation, it is assumed that all $8+$ year old fish are fished at 8 years old .

\section{Recapture rates}

The recapture number in year $\mathrm{j}$ for releases in year $\mathrm{i}$ $\left(\operatorname{Rec} . N_{i j}\right)$ is expressed as:

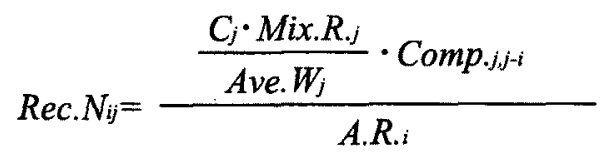

where $C_{j}$ is the commercial catch of red sea bream in year $\mathrm{j}, M i x . R . j$ is the mixture rate, by weight, of DIE fish in year j, Ave. $W_{j}$ is the average weight of DIE fish of year $\mathrm{j}$, Comp.j.j-i is the ratio of $\mathrm{j}$-i year old DIE fish derived from the age composition of DIE fish in year $\mathrm{j}, A . R_{. i}$ is the appearance rate of DIE fish in year $i$.

The total recapture number and the recapture rate of the releases in year i (Rec.Ni, Rec.R.i) are expressed as:

$$
\begin{gathered}
\operatorname{Rec} . N_{i}=\sum_{j=i}^{\mathrm{i}+8} \operatorname{Rec} . N_{i j} \\
\operatorname{Rec} . R_{.}=\frac{\operatorname{Rec} . N_{i}}{\operatorname{Rel} . N_{i}}
\end{gathered}
$$

where $\operatorname{Rel.} N_{i}$ is the number of releases in year $\mathrm{i}$.

\section{Recapture weight, total landing cash value and economic return rates}

The recapture weight in year $\mathrm{j}$ for releases in year $\mathrm{i}$ $\left(\operatorname{Rec} . W_{i j}\right)$ is expressed as:

$$
\operatorname{Rec} . W_{i j}=\operatorname{Rec} . N_{i j} \cdot W_{j-i+0.5}
$$

where $W_{j-i+0.5}$ is the weight of $\mathrm{j}-\mathrm{i}+0.5$ year old red sea bream derived from the growth formula for red sea bream of Kagoshima Bay. ${ }^{2)}$

The total recapture weight, total landing cash value, and the economic return rate of the releases in year $i$ (Rec.Wi, C.V.i, E.R.R.i ) are expressed as:

$$
\begin{gathered}
\operatorname{Rec} . W_{i}=\sum_{\mathrm{j}=\mathrm{i}}^{\mathrm{i}+8} \operatorname{Rec.} W_{i j} \\
\text { C.V.i }=\operatorname{Rec.} W_{i} \cdot \text { Ave.U.P. } . j \\
\text { E.R.R.i }=\frac{\text { C.V.i }}{\text { C.S.i }}
\end{gathered}
$$

where Ave.U.P.ij is the average unit price of red sea bream at the Kagoshima Fish Market from year i to year $\mathrm{j}$ (excluding aquacultured fish), C.S.i is the cost of seed excluding the cost of personnel and facilities.
Table 2 The mixture rate $(\%)$ for DIE fish in fish investigated from 1989 to 2000 .

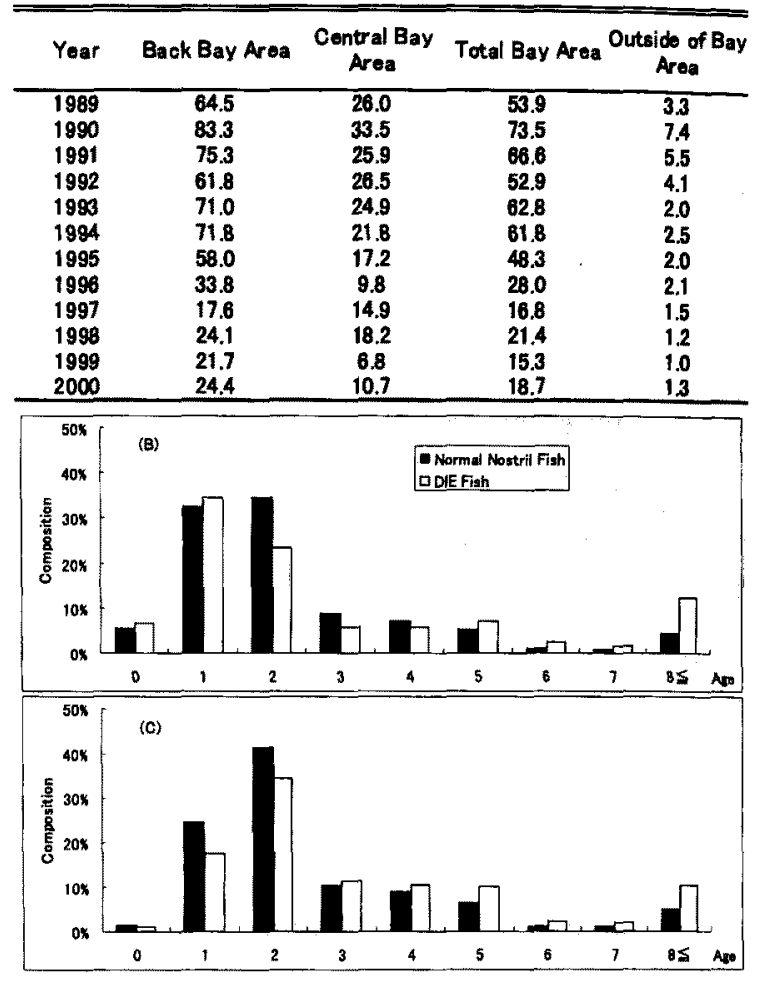

Fig.4 Age composition of a sample in 1999 for normal nostril fish and DIE fish. (B) Back Bay Area, (C)Central Bay Area.

\section{RESULTS}

The mixture rate for DIE fish in fish investigated in this bay, are calculated to be between $15.3 \%$ and $73.5 \%$ from 1989 to 2000 (Table 2). They are between $17.6 \%$ and $83.3 \%$ in the Back Bay Area, $6.8 \%$ to $33.5 \%$ in the Central Bay Area, $1.0 \%$ to $7.4 \%$ in the Outside of Bay Area. Since 1989, red sea bream have been released in the Outside of Bay Area on a scale similar to the other areas, but the mixture rate in this bay, especially in the Back Bay Area, is higher than outside of the bay.

The age composition by sampling in 1999 is shown in Fig.4. For both areas, normal nostril or not, the main fished age classes are 1-2 years old. The life of red sea bream is 20 years old or more, so more than 8 years old fishes are also well landed.

The estimated recapture number and rates for releases from 1989 to 1999 are shown in Table 3. For example, the recapture number and recapture rates in 1990 for 9 years after they were released, were estimated at 92,838 and $8.8 \%$.

The estimated recapture weight, total landing cash value, and the economic return rate for the releases in 1990 are shown in Table 4. They were estimated to be about 73.9 tons, 151.8 million yen, with an economic return rate of 6.99 .

The stocking effectiveness for the releases from 1989 to 1991, for completed 9 year recapture data, 
Table 3 The estimated recapture number and rates for the released year classes from 1989 to 1999.

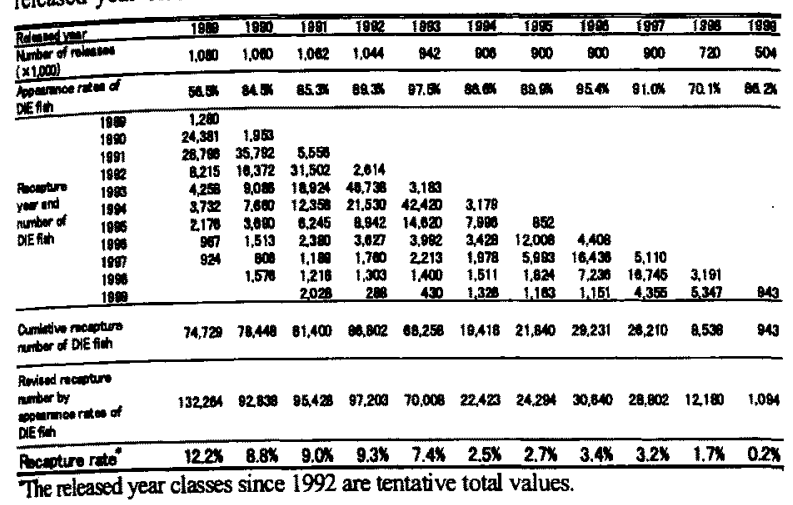

are shown in Table 5. The recapture rates and weights, total landing cash value, and the economic return rates were estimated to be about 9 to $12 \%$ and 74 to 106 tons, 150 to 220 million yen, and 7 to 10 times. There is a possibility that the effectiveness of the releases in 1989 is overestimated, because the appearance rate of DIE fish is lower than that of other years (Table 3 ).

\section{DISCUSSION}

Now, the method of the fish market census to estimate the stocking effectiveness is widely adopted regardless of species. The research on the stocking effectiveness of red sea bream in Kagoshima Bay is the first case of them."

The definition of the stocking effectiveness is still ambiguous. The mixture rate, recapture rate, total landing cash value, and the economic return rate are adopted as the criteria for this paper. There are few cases in which the economic effectiveness is evaluated in detail for red sea bream stockings. Additionally, it is rare that such high recapture rates and economic return rates are estimated. Upon closer look, the "total landing cash value" does not represent profit but only gross sales. The profit should be estimated by multiplying the rate of profitability to the gross sales in the future.

Through this evaluation, such conclusion should not be found out that fishermen should practice red sea bream stockings unilaterally in this bay. In fact, the stocking technology employed is one of the most important methods in which to artificially control this natural resource. Governments and local public organizations have the responsibility to manage such coastal resources. Therefore, stockings should be deliberately practiced by them.

\section{ACKNOWLEDGMENTS}

I thank Dr. Y. Masuda, and foreign students Shirley L. Miagao, Vladimir P. Granada, and Greg N. Nishihara ( Kagoshima University Fisheries Department ) for their useful advice on my
Table 4 The estimated recapture weight and economic return rate for releases in 1990 .

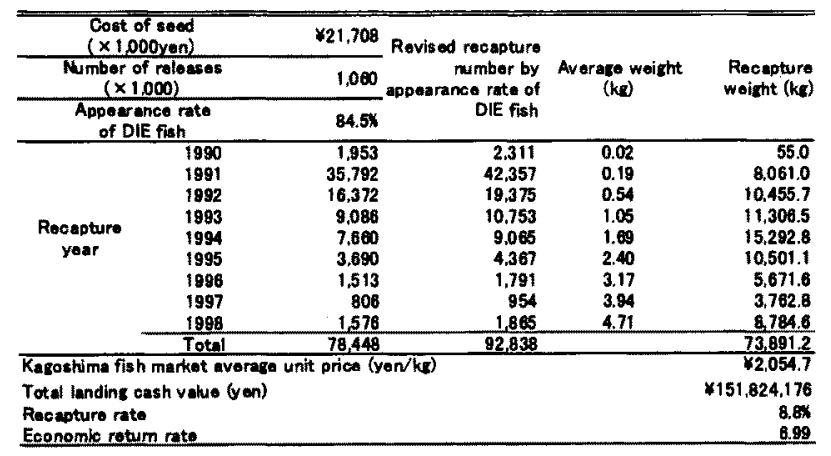

Table 5 The stocking effectiveness for releases from 1989 to 1991.

\begin{tabular}{|c|c|c|c|}
\hline Roleased year & 1989 & 1990 & 1991 \\
\hline $\begin{array}{l}\text { Released number ( } \times 1,000) \\
\text { Cost of seeds (million yen) }\end{array}$ & $\begin{array}{r}1,080 \\
21.3\end{array}$ & $\begin{array}{r}1,060 \\
21.7\end{array}$ & $\begin{array}{r}1,062 \\
18.3 \\
\end{array}$ \\
\hline $\begin{array}{l}\text { Recapture number } \\
\text { Recapture rate }\end{array}$ & $\begin{array}{r}132,264 \\
12.2 \%\end{array}$ & $\begin{array}{r}92,838 \\
8.8 \%\end{array}$ & $\begin{array}{r}95,428 \\
9.0 \%\end{array}$ \\
\hline $\begin{array}{l}\text { Recapture weight (tons) } \\
\text { Total landing cash value } \\
\text { (million yen) } \\
\text { Economic return rate }\end{array}$ & $\begin{array}{l}222.4 \\
10.42\end{array}$ & $\begin{array}{r}151.8 \\
6.99 \\
\end{array}$ & $\begin{array}{r}147.7 \\
8.06 \\
\end{array}$ \\
\hline
\end{tabular}

presentation and this paper. I respect and thank the predecessors for their acquisition, accumulation, and analysis of related data.

\section{REFERENCES}

1. Japan Sea-Farming Association. Seed production and release for sea farming in 1999. 2001 (in Japanese).

2. Shiihara $H$. Results and further problems of releasing in Kagoshima Bay. In: Tanaka M, Matsumiya Y(eds). Sea farming technology of red sea bream. Koseisha Koseikaku, Tokyo, 1986; 106-126 (in Japanese).

3. Sakurai M, Maeda A, Sugimori Y, Kubota M. Process of water exchange through the mouth of Kagoshima Bay. Oceanogr. Jap. 2000; 9: 1-12.

4. Goto M. Deformity of inter-nostril epidermis observed in cultured red sea bream. Saibai Giken 1986; 15: 87-88 (in Japanese).

5. Sobajima $N$, Munekiyo $M$, Funata $H$. Possibility of differentation between the artificially-released and the wild red sea bream by means of the lack of the inter-nostril epidermis. Bull. Kyoto. Ocea. Fish. Sci. 1986; 10: 35-40.

6. Anraku K, Masuda T, Kawamura G, Mana RR. Development of the inter-nostril epidermis in hatchery reared red sea bream, pagrus major. Nippon Suisan Gakkaishi 1999; 65: 501-502.

7. Yamazaki A. Deformities of the pectoral fin and inter-nostril epidermis and the discrimination of the artificially produced and wild red sea bream pagrus major in release-recapture research. Saibai Giken 1998; 26: 61-65.

8. Shishidou H. Pilot project to increase migrant resources (red sea bream), Bull. Kagoshima. Pref. Fish. Exp. Stn. vol. Fish. Div. (1998). 2000; 258-265 (in Japanese).

9. Kitada $S$. The pursuit of stocking effectiveness (1). Aquanet 1999; 2(1): $42-44$ (in Japanese). 